\title{
APLIKASI SISTEM INFORMASI DESA SEBAGAI TEKNOLOGI TEPAT GUNA UNTUK PENDATAAN PENDUDUK DAN POTENSI DESA
}

\author{
Syaharuddin ${ }^{1}$ \\ ${ }^{1}$ Pendidikan Matematika, Universitas Muhammadiyah Mataram, abialmusthafa@gmail.com
}

\begin{abstract}
ABSTRAK
Abstrak: Di Indonesia Sistem Informasi Desa (SID) diatur dalam Undang-undang terkait indikator, tata pengembangan, dan pengelolaannya agar input-output dari teknologi tepat guna ini benar-benar mendeskripsikan data dan informasi desa tersebut. Hal ini dikarenakan dana pembangunan desa akan terealisasikan dengan baik dan tepat sasaran. Dalam kegiatan ini tim melakukan survey ke beberapa lokasi di Lombok Tengah khususnya beberapa desa pemekaran yang memang membutuhkan tenaga ahli sebagai operator dan system informasi desa yang komunikatif dengan user sehingga memudahkan dalam penginputan data dan mengeksport data dalam sebuah laporan. Sistem dibangun berdasarkan garis besar peraturan pemerintah dan masukan atau saran dari pejabat setempat sehingga menghasilkan beberapa menu input-output meliputi Data Profil Desa, Data Kependudukan, Data Pendidikan, Data Potensi Wisata Desa, Data Administrasi termasuk surat masuk dan keluar, Data Inventaris Desa, dan Data Pendapatan dan Pengeluaran Desa. Aplikasi ini dibangun menggunakan Delphi sebagai Graphical User Interface, Microsoft Access sebagai Bank Data, dan Microsoft Excell sebagai export data atau pelaporan.
\end{abstract}

Kata Kunci: SID, GUI, MS Access.

\begin{abstract}
In Indonesia the Village Information System (SID) is regulated in the Law regarding the indicators, governance of development, and management so that inputoutput of these appropriate technologies actually describes the data and information of the village. This is because the village development funds will be realized well and on target. In this activity the team conducted a survey to several locations in Central Lombok, especially some pemekaran villages that do require experts as operators and village information system communicative with the user making it easier in inputting data and exporting data in a report. The system builds on the outline of government regulations and inputs or suggestions from local officials resulting in multiple inputoutput menus including Village Profile Data, Population Data, Educational Data, Village Tourism Potential Data, Administrative Data including incoming and outgoing letters, Village Inventory Data, and Village Revenue and Expenditure Data. This application is built using Delphi as Graphical User Interface, Microsoft Access as Data Bank, and Microsoft Excel as export data or reporting.
\end{abstract}

Keywords: SID, GUI, MS AccesS

Riwayat Artikel: Diterima: 04-11-2017, Disetujui: 07-12-2017 


\section{A. LATAR BELAKANG}

Proses pemekeran mulai tingkat provinsi sampai desa bukanlah suatu hal yang menyenangkan pada proses awal, karena dibutuhkan kerja keras untuk membangun SDM yang handal dan sistem informasi yang layak dikonsumsi masyarakat. Di Indonesia, dengan adanya pendanaan terstruktur dan harus tepat guna dibutuhkan Sistem Informasi Desa (SID) yang mengedepankan kecepatan, ketepatan, dan keabsahan. Sehingga SID ini lumayan membutuhkan tenaga dan waktu yang banyak dalam proses pengelolaannya. Karena SID menjadi inti informasi dari sebuah desa yang langsung di atur oleh Undang-undang. Disampaikan bahwa Sistem Informasi Desa (SID) menjadi bagian tak terpisahkan dari pembangunan desa dan pembangunan kawasan perdesaan termasuk potensi-potensi desa yang harus dikembangkan agar bisa menjadi profit ekonomi yang cukup signifikan bagi desa tersebut. Dengan adanya perubahan paradigma pembangunan desa membuat SID menjadi penting peranannya. Karena itu, perlu dikembangkan SID yang sesuai dengan visi Undang-undang Desa yakni menjadikan desa kuat, mandiri, sejahtera, dan demokratis. Oleh karenanya, SID diatur secara khusus dalam UU Desa melalui Pasal 86 ayat (2) dan ayat (5) mewajibkan kepada Pemerintah dan Pemerintah Daerah untuk mengembangkan SID, dan pengelolaannya dilakukan oleh Pemerintah Desa agar dapat diakses oleh masyarakat desa dan pemangku kepentingan lainnya. Pada ayat (4) dijelaskan bahwa Sistem Informasi Desa (SID) sebagaimana dimaksud pada ayat (2) meliputi data Desa, data Pembangunan Desa, Kawasan Perdesaan, serta informasi lain yang berkaitan dengan Pembangunan Desa dan pembangunan Kawasan Perdesaan.

Tahun 2017 ini sudah banyak SID yang dikembangkan di berbagai daerah di Indonesia, terutama juga di kawasan Lombok Tengah Provinsi NTB. Namun informasi yang disajikan sangat minim, artinya belum bisa memenuhi indikator yang tertera dalam UU Desa Pasal 86 tersebut. Misalnya ambil salah satu Desa Setiling Kabupaten Lombok Tengah. Berdasarkan hasil penulusan peneliti, hal ini juga disebabkan karena tingkat sinyal internet untuk online di Desa Setiling masih kurang kuat, di samping data-data yang diupload juga sangat kurang. Oleh sebab itu perlu dikembangkan SID yang mampu dijadikan Local Community Information and Tekcnology Service (LCITS) di desa ini. Salah satu aplikasi terbaru dalam sistem basis data berbasis Delphi yang terkoneksi dengan Microsoft Access dan Excell. Pemilihan aplikasi ini sebagai standar ketika sinyal internet tidak ada, sehingga masih bisa digunakan ketika offline.

\section{B. METODE PELAKSANAAN}

Kegiatan ini dilakukan menggunakan teknik observasi dan interview dalam pengumpulan data. Sedangkan pelaksanaan dilakukan di dua tempat yakni di Laboratorium Matematika untuk mengembangkan SID dan lingkungan atau Desa Setiling untuk mengumpulkan data terkait kependudukan dan potensi desa.

Adapun tahapan dalam kegiatan pengabdian ini terdiri dari 4 tahap yakni:

1. Survey lapangan. Kegiatan ini dilakukan untuk melihat kondisi awal sebagai kebutuhan dari SID nantinya, termasuk survey sistem 
administrasi Desa, kegiatan dan kondisi penduduk, serta potensi desa.

2. Pengembangan SID. Pada tahap ini tim mengembangkan SID menggunakan Delphi sebagai GUI dan Ms Access sebagai bank data.

3. Pengambilan dan Penginputan Data. Pada tahap ini tim mengumpulkan data di Kantor Desa terkait sistem administrasi termasuk surat menyurat, profil desa, surat menyurat, sedangkan di masyarakat melakukan sensus penduduk dengan cara mengumpulkan Kartu Keluarga dan identitas lainnya, serta melakukan pengambilan data terkait potensi desa termasuk wisata desa.

4. Sosialisasi. Pada tahap ini tim melakukan sosialisasi hasil SID kepada perangkat desa.

\section{HASIL DAN PEMBAHASAN}

\section{Aplikasi SID}

Aplikasi SID telah dikembangkan menggunakan Delphi sebagai GUI dan Ms Access sebagai Bank Data, dan Ms Excell sebagai export data jika butuhkan untuk pelaporan. Adapun flowchart sederhana penggunaan SID sebagai berikut:

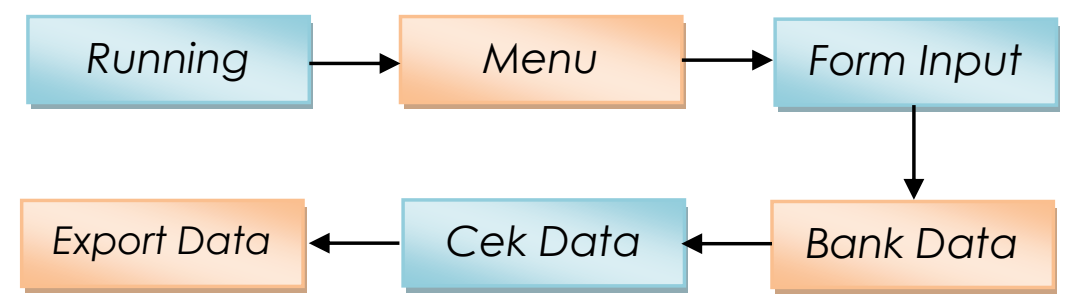

Gambar 1. Alur Penggunaan SID

Pengguna dapat melakukan running melalui desktop dengan mengklik icon SID. Kemudian memilih menu yang sudah ada atau sesuai data yang akan diinputkan. Jika sudah melakukan penginputan melalui tombol "Simpan", maka dicek kembali data tersebut di bank data. Adapun cara pengecekan dipilih berdasarkan kategori yang ada. Kemudian diinputkan kata kunci di kolom "edit", maka secara otomatis aplikasi akan melakuka filter data. Jika pengguna ingin melakukan export data melalui Ms Excell, tinggal memilih tombol export. Selanjutnya bisa dilakukan pengaturan sesuai kebutuhan. 


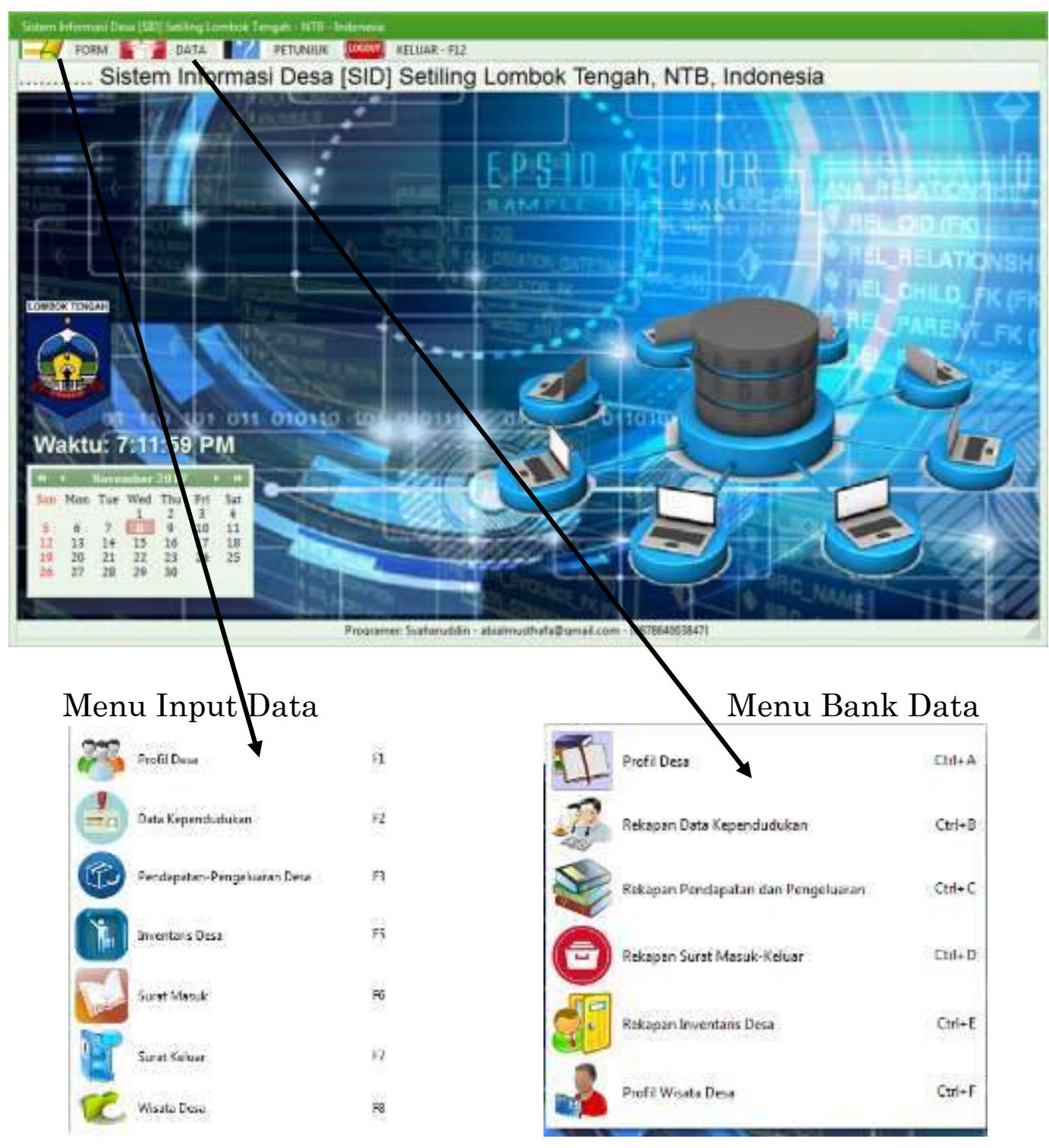

Sistem Informasi Desa (SID) yang telah dikembangkan terdiri dari 3 menu utama yakni Menu Form, Menu Data, Menu Petunjuk, dan Menu Keluar. Pada Menu Form, pengguna yang ingin menginputkan data atau informasi baru dilakukan lewat menu ini, para pengguna tinggal memilih Form data yang akan diinputkan. Sedangkan Menu Data berisi data dalam bentuk tabel yang sudah diisi lewat Menu Form, pada menu ini pengguna bisa melakukan pencarian data berdasarkan kategori. Jika diperlukan melakukan print atau pelaporan bisa meng-klik tombol export.

Kemudian pada Menu Petunjuk berisi (1) Petunjuk Penggunaan Aplikasi dan (2) Biografi Programer. Petunjuk ini akan mempermudah pengguna jika terjadi error atau merasa belum paham dengan tata cara penggunaan program sehingga dengan membacanya terlebih dahulu akan mempermudah pengguna dalam mengoperasikan program ini. Terakhir, menu keluar untuk keluar dari aplikasi (program).

Sedangkan form input masing-masing basis data dijelaskan pada Tabel 1 berikut ini. 
TABEL 1

FORM INPUTAN DAN TAMPILANNYA

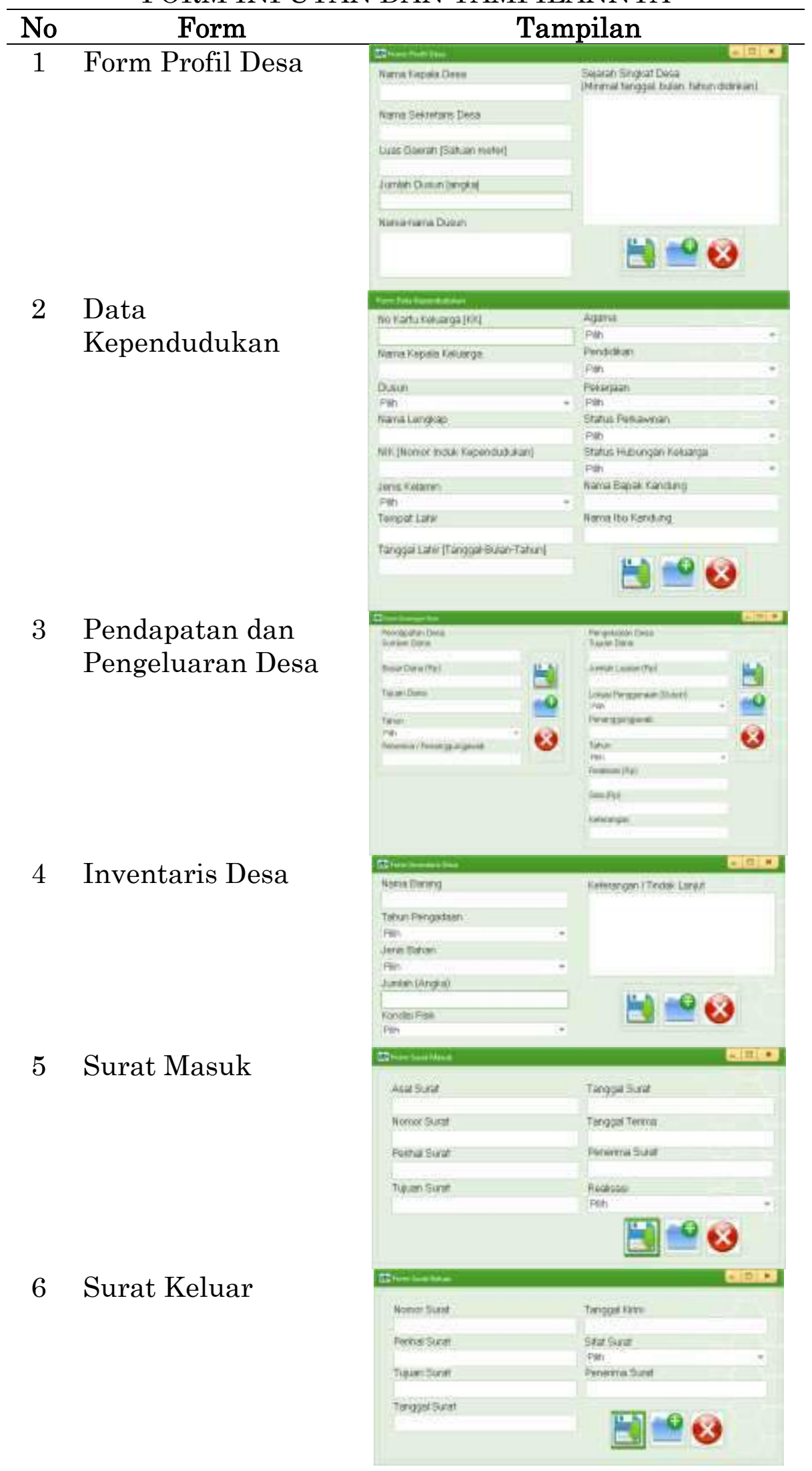




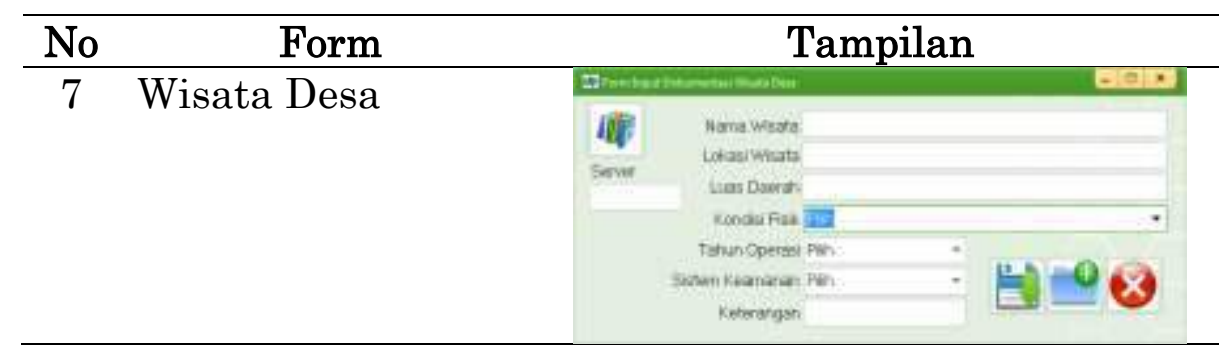

\section{Output Data}

\section{a. Penggunaan Luas Lahan}

Penggunaan lahan di Desa Setiling lebih banyak dikelola untuk perkebunan. Adapun hasil perkebunan seperti jeruk, alpukat, mangga, rambutan, manggis, salak, papaya, durian, sawo, nangka, duku, dan pisang.

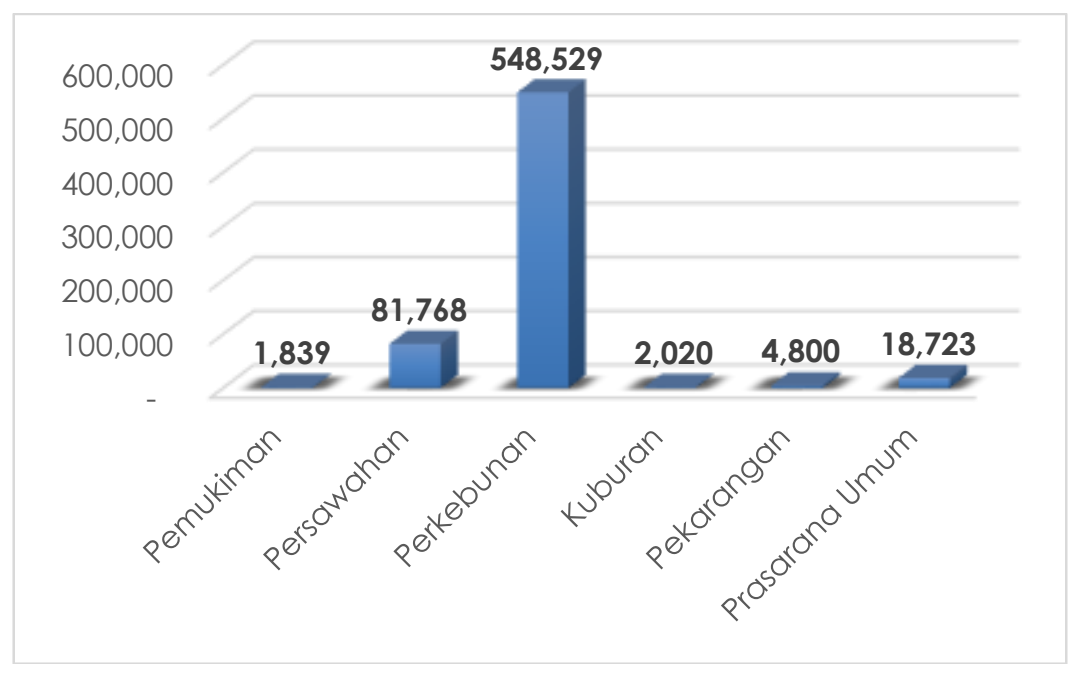

Gambar 1. Statistik Penggunaan Lahan Desa Setiling

\section{b. Data Penduduk}

Sedangkan perkembangan penduduk Desa Setiling dijelaskan oleh Gambar 3 berikut.

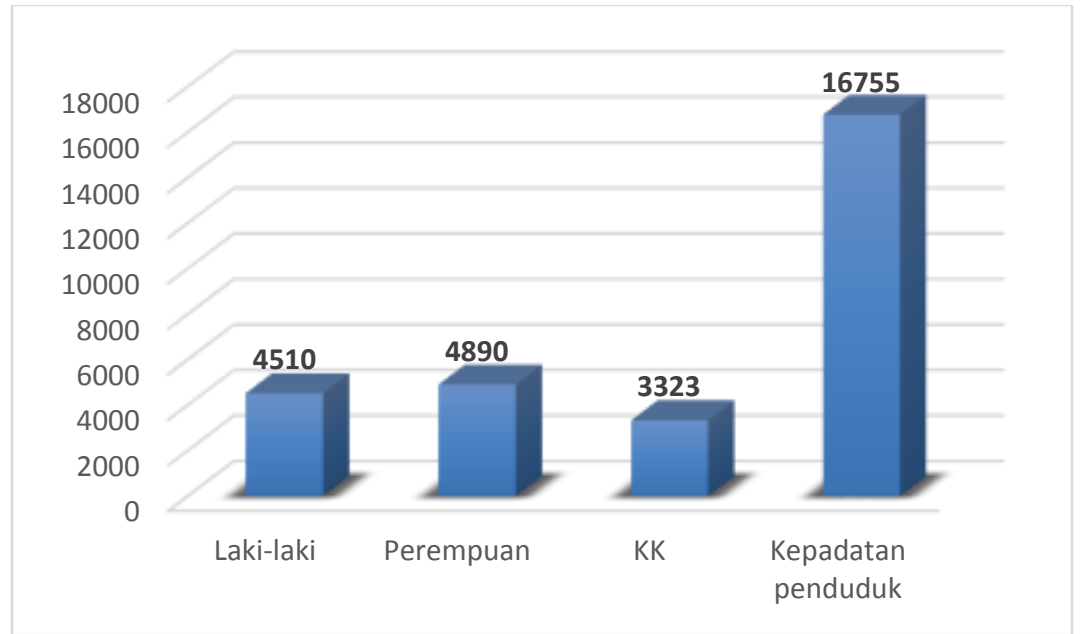

Gambar 3. Jumlah Penduduk Desa Setiling 
c. Data Pendidikan

Kondisi pendidikan di Desa Setiling bervariasi mulai dari jenjang TK sampai perguruan tinggi. Adapun pola sebarannya sesuai Gambar 4 berikut.

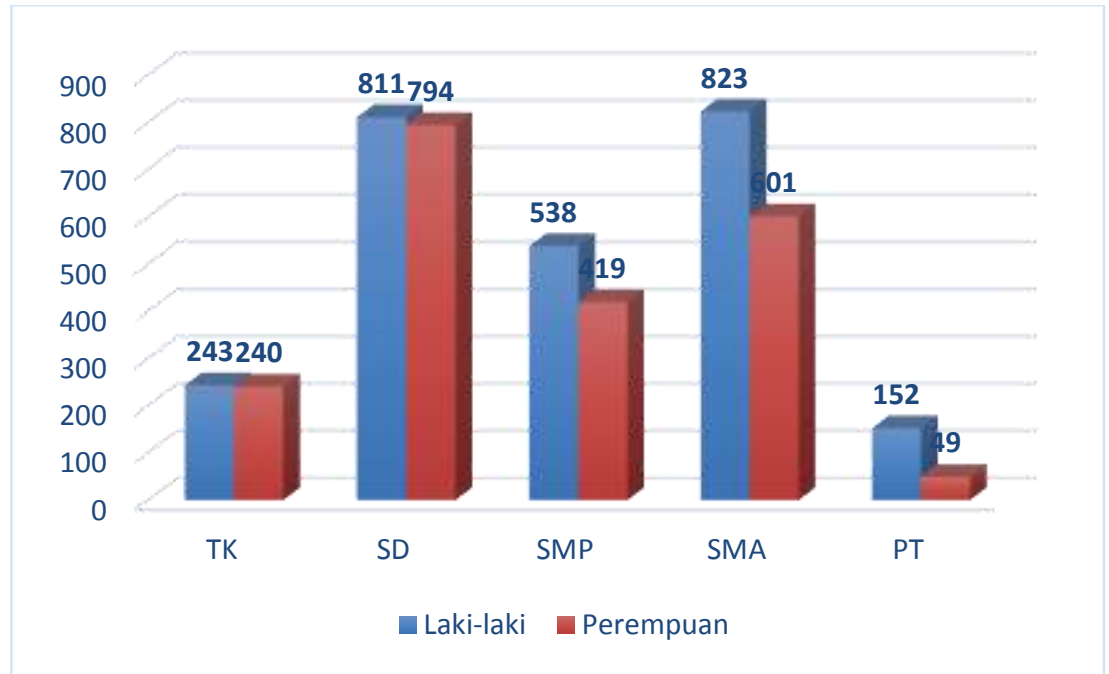

Gambar 4. Jumlah Penduduk Bidang Pendidikan

\section{DISKUSI}

Salah satu indikator sebuah daerah atau Desa dikatakan maju jika secara data administratif terekam dengan baik, meliputi data kependudukan, pendidikan, ekonomi, penggunaan lahan (pertanian dan perkebunan). Karena data inilah menjadi dasar kebijakan pemerintah untuk memberikan penyuluhan, pemberian dana, dan menjadikan contoh bagi daerah-daerah yang lain. Satu sisi, di Indonesia saat ini terdapat program pemerintah untuk membangun infrastruktur dan administrasi lainnya dengan cara memberikan dana masing-masng desa sebesar $1 \mathrm{M}$, bahkan pada tahun 2018 mendatang pemerintah secara total menurunkan dana desa sebesar 199,8 M. Tentu dana ini bukan dana yang sedikit, sehingga dibutuhkan sistem perekam data atau informasi desa yang cepat dan akurat agar segala pendapatan dan pengeluaran desa direkam sebaikbaiknya untuk menghindari penggunaan dana diluar Rencana Anggaran Belanja (RAB).

Fakta di lapangan masih banyak desa yang belum memiliki sistem informasi desa yang cepat dan akurat. Padahal sistem informasi desa ini sudah diatur dalam Undang-undang Perdesaan. Oleh sebab itu, perlu perhatian khusus dari pemerintah untuk membuat sistem yang lebih handal di setiap desa dan menunjuk seorang ataupun tim yang menangani sistem informasi ini agar setiap ada data atau informasi baru langsung direkam atau diinputkan ke sistem informasi desa tersebut.

\section{E. SIMPULAN DAN SARAN}

Adapun beberapa kesimpulan yang diperoleh dari kegiatan ini sebagai berikut:

1. Perangkat Desa Setiling merasa senang karena melalui kegiatan ini terciptanya Sistem Informasi Desa (SID) yang mampu merekam berbagai perkembangan dan pembangunan desa. 
2. Sistem Informasi Desa (SID) yang dikembangkan terdiri dari 6 menu yakni Profil Desa, Rekapan Data Kependudukan, Rekapan Data Pendapatan dan Pengeluaran Desa, Rekapan Data Administrasi termasuk Surat Masuk dan Keluar, Rekapan Data Inventaris Desa, dan Profil Wisata Desa.

Berdasarkan hasil pengabdian ini, kami bisa memberikan saran untuk kegiatan pengabdian selanjutnya, yakni:

1. Dana Pengabdian sebaiknya ditingkatkan agar kegiatan ini bisa dilakukan dengan jangka waktu yang lebih lama, lokasi yang luas, dan jumlah desa yang banyak.

2. Pihak perangkat Desa Setiling hendaknya untuk terus meng-update atau penginputan data ke SID yang sudah dikembangkan.

\section{UCAPAN TERIMA KASIH}

Tim penulis mengucapkan terima kasih kepada Lembaga Pengabdian Masyarakat (LPM) Universitas Muhammadiyah Mataram yang telah mendanai kegiatan pengabdian ini sehingga terlaksana dengan baik.

\section{DAFTAR RUJUKAN}

[1] Almerich, G., dkk. 2016. "Teachers Information and Communication Technology Competences: A Structural Approach”. Computer \& Education. 100. h. 110-125, 2016.

[2] DP2M Dikti. Buku Panduan Pelaksanaan Penelitian dan Pengabdian Kepada Masyarakat Edisi XI Tahun 2017. Jakarta, 2017.

[3] LPM UM Mataram. Pedoman Pengabdian Kepada Masyarakat dan Prosedur Penulisan Proposal. Universitas Muhammadiyah Mataram, 2017.

[4] Syafiul Muzid dan Noor Latifah, Pengembangan Sistem Layanan Informasi Desa (Silisa) Terintegrasi Berbasis SMS Gateway", Prosiding SNATIF, h. 407412, 2017.

[5] Suryati, Bambang Eka Purnama, "Pembangunan Sistem Informasi Pendataan Rakyat Miskin Untuk Program Beras Miskin (Raskin) Pada Desa Mantren Kecamatan Kebonagung Kabupaten Pacitan", Journal Speed - Sentra Penelitian Engineering dan Edukasi, Vol. 2, No. 4, 2010.

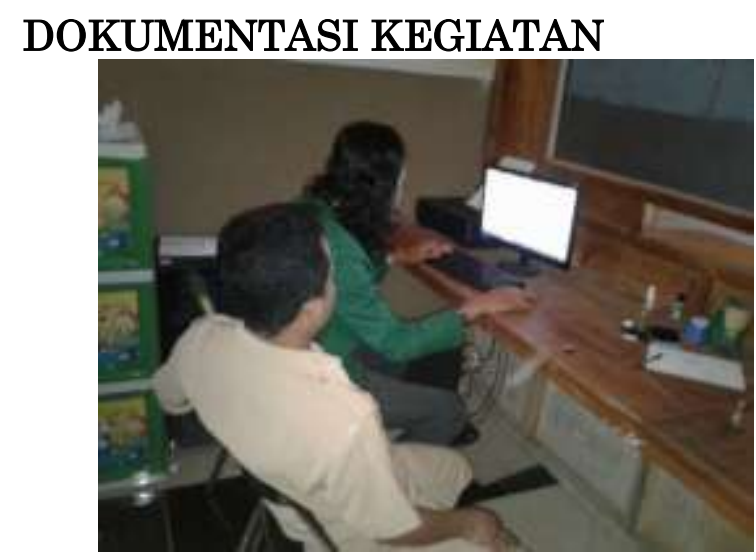

Proses Penginputan Data

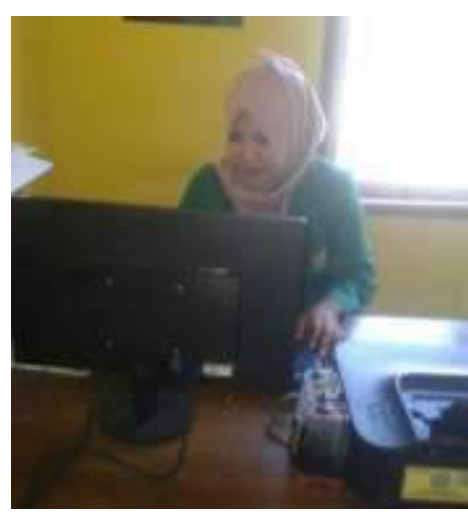

Proses Penginputan Data 